\title{
Internet-based tapering of oral corticosteroids in severe asthma: a pragmatic randomised controlled trial
}

\author{
Simone Hashimoto, ${ }^{1}$ Anneke Ten Brinke, ${ }^{2}$ Albert C Roldaan, ${ }^{3}$ llonka H van Veen, ${ }^{4}$ \\ Gertrude M Möller, ${ }^{5}$ Jacob K Sont, ${ }^{6}$ Els J M Weersink, ${ }^{1}$ Jaring $S$ van der Zee, ${ }^{1}$ \\ Gert-Jan Braunstahl, ${ }^{7}$ Aeilko H Zwinderman, ${ }^{8}$ Peter J Sterk, ${ }^{1}$ Elisabeth $\mathrm{H} \mathrm{Bel}^{1}$
}

'Department of Respiratory Medicine, Academic Medical Centre, University of

Amsterdam, Amsterdam, The Netherlands

${ }^{2}$ Department of Pulmonology, Medical Centre Leeuwarden, Leeuwarden, The Netherlands ${ }^{3}$ Department of Pulmonology, Haga Ziekenhuis, Den Haag, The Netherlands

${ }^{4}$ Department of Pulmonology, Medisch Spectrum Twente, Enschede, The Netherlands ${ }^{5}$ Department of Pulmonology, Leiden University Medical Centre, Leiden, The Netherlands ${ }^{6}$ Department of Medical Decision Making, Leiden University Medical Centre, Leiden, The Netherlands ${ }^{7}$ Department of Pulmonary Medicine, St Franciscus Gasthuis, Rotterdam, The Netherlands

${ }^{8}$ Department of Clinical Epidemiology and Biostatistics, Academic Medical Centre, University of Amsterdam, The Netherlands

\section{Correspondence to}

Simone Hashimoto, Department of Respiratory Medicine, Academic Medical Centre University of Amsterdam, F5-260, Meibergdreef 9, Amsterdam $1105 \mathrm{AZ}$, The Netherlands;

s.hashimoto@amc.nl

Received 3 December 2010 Accepted 24 February 2011 Published Online First 7 April 2011

\section{ABSTRACT}

Background In patients with prednisone-dependent asthma the dose of oral corticosteroids should be adjusted to the lowest possible level to reduce long-term adverse effects. However, the optimal strategy for tapering oral corticosteroids is unknown.

Objective To investigate whether an internet-based management tool including home monitoring of symptoms, lung function and fraction of exhaled nitric oxide $\left(\mathrm{FE}_{\mathrm{NO}}\right)$ facilitates tapering of oral corticosteroids and leads to reduction of corticosteroid consumption without worsening asthma control or asthma-related quality of life. Methods In a 6-month pragmatic randomised prospective multicentre study, 95 adults with prednisone-dependent asthma from six pulmonary outpatient clinics were allocated to two tapering strategies: according to conventional treatment $(n=43)$ or guided by a novel internet-based monitoring system (internet strategy) $(n=52)$. Primary outcomes were cumulative sparing of prednisone, asthma control and asthma-related quality of life. Secondary outcomes were forced expiratory volume in $1 \mathrm{~s}\left(\mathrm{FEV}_{1}\right)$, exacerbations, hospitalisations and patient's satisfaction with the tapering strategy.

Results Median cumulative sparing of prednisone was 205 (25-75th percentile -221 to 777) $\mathrm{mg}$ in the internet strategy group compared with $0(-497$ to 282) $\mathrm{mg}$ in the conventional treatment group $(p=0.02)$. Changes in prednisone dose (mixed effect regression model) from baseline were $-4.79 \mathrm{mg} /$ day and $+1.59 \mathrm{mg} /$ day, respectively $(\mathrm{p}<0.001)$. Asthma control, asthma-related quality of life, $\mathrm{FEV}_{1}$, exacerbations, hospitalisations and satisfaction with the strategy were not different between groups.

Conclusions An internet-based management tool including home monitoring of symptoms, lung function and $\mathrm{FE}_{\mathrm{NO}}$ in severe asthma is superior to conventional treatment in reducing total corticosteroid consumption without compromising asthma control or asthma-related quality of life.

Clinical trial registration number Clinical trial registered with http://www.trialregister.nl (Netherlands Trial Register number 1146).

\section{INTRODUCTION}

Despite the regular use of high doses of inhaled corticosteroids (ICS) and long-acting bronchodilators, patients with severe asthma may require frequent bursts or even depend on daily oral corticosteroids. ${ }^{12}$ In the majority of these patients

\section{Key messages}

What is the key question?

- Oral corticosteroids should be used in the lowest possible dose in patients with severe asthma to prevent adverse effects. We investigated whether an Internet-based management tool is superior to doctor's decision alone to reduce oral corticosteroid consumption.

What is the bottom line?

- An internet-based management tool including home monitoring of symptoms, lung function and $\mathrm{FE}_{\mathrm{NO}}$ in severe asthma leads to significant reduction in total oral corticosteroid consumption as compared to doctor's decision alone.

\section{Why read on?}

- This article provides a detailed description of the internet-based management tool that is not only ideal for use in clinical practice, but also suitable to assess outcome in clinical trials with novel anti-inflammatory steroid-sparing drugs.

the use of systemic corticosteroids leads to serious adverse effects including osteoporosis, bone fractures, ${ }^{3}$ diabetes, hypertension, cataract and muscle weakness. $^{4}$ These adverse effects may seriously affect patients' quality of life and have considerable public health implications. ${ }^{5}$ Since adverse effects are dose- and time-dependent, systemic corticosteroids should be used in the lowest possible dose. ${ }^{346}$

Tapering oral corticosteroids in patients with severe asthma remains a challenge. ${ }^{7}$ These patients-although relatively few-generally require considerable time and resources because their disease is often complicated by comorbidities, ${ }^{8}$ steroid resistance ${ }^{9}$ and fixed airflow limitation. ${ }^{10}$ Moreover, patients with a suppressed hypothalamic-pituitary-adrenal axis or psychological dependencies may have unpredictable or unsuspected responses to tapering. ${ }^{11}$ This is why patients are often prescribed higher doses of oral corticosteroids than are strictly indicated, which leads to unnecessarily high cumulative doses of oral corticosteroids. ${ }^{10}$

Currently, there are no guidelines on how to taper oral corticosteroids safely in severe asthma. ${ }^{6}$ Clinicians generally make occasional attempts to reduce the dose of oral corticosteroids based on 
symptoms, physical signs and lung function. Ideally, tapering should be a continuous, dynamic and personalised process based on frequent evaluations, objective parameters of disease severity and constant monitoring of risks. In conventional settings it can be quite complicated to achieve this ideal situation, both for patients and physicians. Internet-based management strategies have therefore been developed to enhance the feasibility and effectiveness of intensive monitoring. Many examples of internet-based applications can be found in the management of chronic diseases and severe patients including HIV, ${ }^{12}$ diabetes, ${ }^{13}$ hypertension, ${ }^{14}$ asthma ${ }^{15}{ }^{16}$ and lung transplantation. ${ }^{17}$ The recent development of hand-held devices to measure lung function and exhaled biomarkers at home also provide new opportunities for more frequent and accurate adjustments of asthma therapy. ${ }^{18}$

Comparative effectiveness research is increasingly applied in asthma to evaluate the outcome of clinical interventions. ${ }^{15} 1920$ It provides the basis for rational decision-making about the care of individual patients with asthma and how best to deliver this care in real-world settings. ${ }^{21}$ We therefore designed this pragmatic randomised clinical trial to assess the outcome (cumulative dose of oral corticosteroids, asthma control and asthmarelated quality of life) of an internet-based management tool in comparison with conventional asthma treatment over a period of 6 months.

\section{METHODS}

\section{Subjects}

Eligible patients were adults (18-75 years) with a diagnosis of severe refractory asthma according to the major and minor criteria recommended by the American Thoracic Society. ${ }^{1}$ They had uncontrolled asthma despite intensive follow-up by an asthma specialist for at least 1 year, chronic treatment with oral corticosteroids and high doses of ICS plus long-acting bronchodilators. All were non-smokers with a maximum smoking history of 15 pack-years and had access to internet or mobile telephone.

\section{Study design}

We conducted a 6-month pragmatic prospective randomised controlled study involving outpatients from two academic tertiary care hospitals and four large community hospitals in The Netherlands. The study was designed according to the CONSORT recommendations for pragmatic trials. ${ }^{22}$ Patients were randomly allocated to one of two strategies: dose adjustment of oral corticosteroids guided by an internet-based management tool (internet group) or according to conventional asthma treatment by the pulmonologist (conventional management group). All patients were followed for 6 months and had the same monthly follow-up visit at their own pulmonologist. Pulmonologists were instructed not to change the maintenance dose of ICS during the study unless strictly necessary on clinical grounds.

\section{Internet group}

The internet-based management tool comprised (1) an electronic diary; (2) treatment decision support for the patients; and (3) monitoring support by a study nurse.

\section{Electronic diary}

Patients recorded symptoms, registered their dose of oral corticosteroids, lung function using a hand-held spirometer (Piko-1; Ferraris Respiratory, Hertford, UK) and exhaled nitric oxide
$\left(\mathrm{FE}_{\mathrm{NO}}\right.$ ) using a hand-held $\mathrm{NO}$ analyser (Niox Mino; Aerocrine $\mathrm{AB}$, Solna, Sweden) before medicine intake on a daily basis. ${ }^{23}$ Asthma control questionnaires (ACQ) ${ }^{24}$ were completed weekly and asthma-related quality of life questionnaires (AOLO) ${ }^{25}$ were completed at baseline and every 3 months thereafter. Patients registered their data via a validated asthma monitoring service using an internet application or SMS messages. ${ }^{16}$ They also registered every event related to asthma such as antibiotic intake, emergency room visits or deterioration of symptoms. At the end of the study patients rated their global satisfaction with the tapering strategy on a 7-point scale ranging from 'absolutely not satisfied' to 'completely satisfied'.

\section{Treatment decision support}

Patients had daily information about their asthma graphically on the web page and received weekly instructions via the web page for stepwise corticosteroid dose adjustments according to a built-in algorithm (table 1). The decision rule of this algorithm was based on week-to-week changes in mean levels of $\mathrm{FE}_{\mathrm{NO}}$ and $\mathrm{ACQ}$ as follows. If asthma remained controlled (change in ACQ $<+0.5)$, the algorithm recommended down-titration by one dose step. If asthma control deteriorated, the algorithm recommended up-titration of the corticosteroid dose only in case of a concomitant increase in $\mathrm{FE}_{\mathrm{NO}}>10 \mathrm{ppb}$; this was to avoid an increase in the dose of oral corticosteroids for reasons other than a flare-up of asthmatic airway inflammation. ${ }^{11}$ The steroid dose was decreased in case of $\mathrm{ACO}>0.5$ but $\mathrm{FE}_{\mathrm{NO}}$ decreased by $>10 \mathrm{ppb}$. In all other instances the algorithm recommended keeping the dose of corticosteroids unchanged.

\section{Monitoring support}

A study nurse was responsible for coaching the patients, monitoring the data entered at the web page and facilitating the communication between patients and pulmonologists.

The pulmonologists were not aware of any of the data registered on the study website but were contacted by the study nurse in case of an imminent exacerbation (decrease in morning $\mathrm{FEV}_{1}$ of at least $10 \%$ compared with mean $\mathrm{FEV}_{1}$ from the week before). In case of an exacerbation they could overrule the internet dose prescription. The tapering algorithm was then interrupted and immediately restarted at the end of the steroid burst.

Table 1 Criteria for dose adjustment of oral corticosteroids in the internet-based management group with corresponding dose steps

Panel A

\begin{tabular}{lll}
\hline & $\Delta$ ACO $\geq+\mathbf{0 . 5}$ & $\boldsymbol{\Delta \text { ACO } < + \mathbf { 0 . 5 }}$ \\
\hline$\Delta \mathrm{FE}_{\mathrm{NO}}>+10 \mathrm{ppb}$ and $>10 \%$ & $\uparrow$ & $\downarrow$ \\
$\Delta \mathrm{FE}_{\mathrm{NO}}>+10 \mathrm{ppb}$ and $\leq 10 \%$ & $=$ & $\downarrow$ \\
$-10 \leq \Delta \mathrm{FE}_{\mathrm{NO}} \leq+10 \mathrm{ppb}$ & $=$ & $\downarrow$ \\
$\Delta \mathrm{FE}_{\mathrm{NO}}<-10 \mathrm{ppb}$ & $\downarrow$ & $\downarrow$
\end{tabular}

Panel B

\begin{tabular}{ll}
\hline Maintenance dose $(\mathbf{m g} /$ day) & Dose steps $(\mathbf{m g} /$ day) \\
\hline$>25$ & Increase or decrease $10 \mathrm{mg}$ \\
$20-25$ & Increase or decrease $5 \mathrm{mg}$ \\
$10-20$ & Increase or decrease $2.5 \mathrm{mg}$ \\
$<10$ & Increase or decrease $2.5 \mathrm{mg}$ \\
& every other day
\end{tabular}

Panel A shows the criteria for dose adjustment of prednisone based on daily $\mathrm{FE}_{\mathrm{NO}}$ values and weekly ACO score. Panel B shows the dose steps for the adjustment of prednisone maintenance dose. $\triangle \mathrm{ACQ}=$ difference of Asthma Control Questionnaire scores between 2 weeks. $\triangle \mathrm{FENO}=$ difference of mean fraction of exhaled nitric oxide between 2 weeks (in parts per billion). $\uparrow$ denotes increase of prednisone dose by one step; $=$ denotes no change in prednisone dose; $\downarrow$ denotes decrease in prednisone dose by one dose step. 


\section{Conventional management group}

Patients in the conventional management group visited the pulmonology outpatient clinic every month and had their oral corticosteroids down-titrated according to the prescription by the pulmonologist. Pulmonologists followed the Global Initiative for Asthma (GINA) guidelines for treatment of patients with severe asthma ${ }^{6}$ and were instructed to down-titrate the dose of oral corticosteroids whenever possible on clinical grounds.

For research purposes the patients in the conventional management group were asked to enter their daily dose of corticosteroids in the study website and, for safety reasons, they also registered symptoms and lung function which were accessible to the study nurse only.

\section{Randomisation and masking}

Randomisation was stratified for study centre and initial oral corticosteroid dose (lower or higher than $10 \mathrm{mg}$ prednisone equivalent/day). Patients were randomised by a computer random number generator and remained on the same allocation throughout the study. The treatment assignments were unblinded after randomisation to allow monthly corticosteroid dose adjustments according to conventional treatment by the physician or weekly adjustments according to the internet algorithm.

\section{Outcome measures}

The primary outcomes were cumulative sparing of oral corticosteroids (actual cumulative dose minus the expected cumulative dose) and (equivalence in) ACQ and AOLO. Secondary outcomes were global satisfaction scale and (equivalence in) $\mathrm{FEV}_{1}$, number of exacerbations and days of hospitalisation. The actual cumulative dose was calculated from the doses registered daily on the website and the expected cumulative dose was extrapolated from the daily dose at study entry. An exacerbation was defined as a decrease in morning $\mathrm{FEV}_{1}$ of at least $10 \%$ compared with the mean $\mathrm{FEV}_{1}$ from the week before, or a respiratory event requiring an increase in prednisone equivalent to at least $10 \mathrm{mg} /$ day, or a course of antibiotics, with or without hospitalisation.

Newly diagnosed severe adverse effects of corticosteroid use during the study were documented for safety reasons.

\section{Statistical analysis}

The sample size was based on demonstrating equivalence in asthma control between the two groups based on ACQ as the primary outcome measure. The minimal clinically important change in ACQ has been shown to be $0.5 .^{24}$ A sample size of 50 patients per group was enough to detect a difference of 0.39 points or more in ACQ between the two groups ( $\alpha=0.05$ two-sided, $\beta=0.20$ one-sided).

Data analysis using SPSS Version 15.0 was carried out according to a pre-established analysis plan and no interim analysis was done. Between-group comparisons of normally and non-normally distributed data were performed with the use of the Student $t$ test and the Mann-Whitney $U$ test, respectively. Repeated measurements of oral corticosteroid usage were
Figure 1 Assessment, randomisation and follow-up of the study patients. Randomisation was stratified but without blocking, which explains the unequal number of patients in each study group.

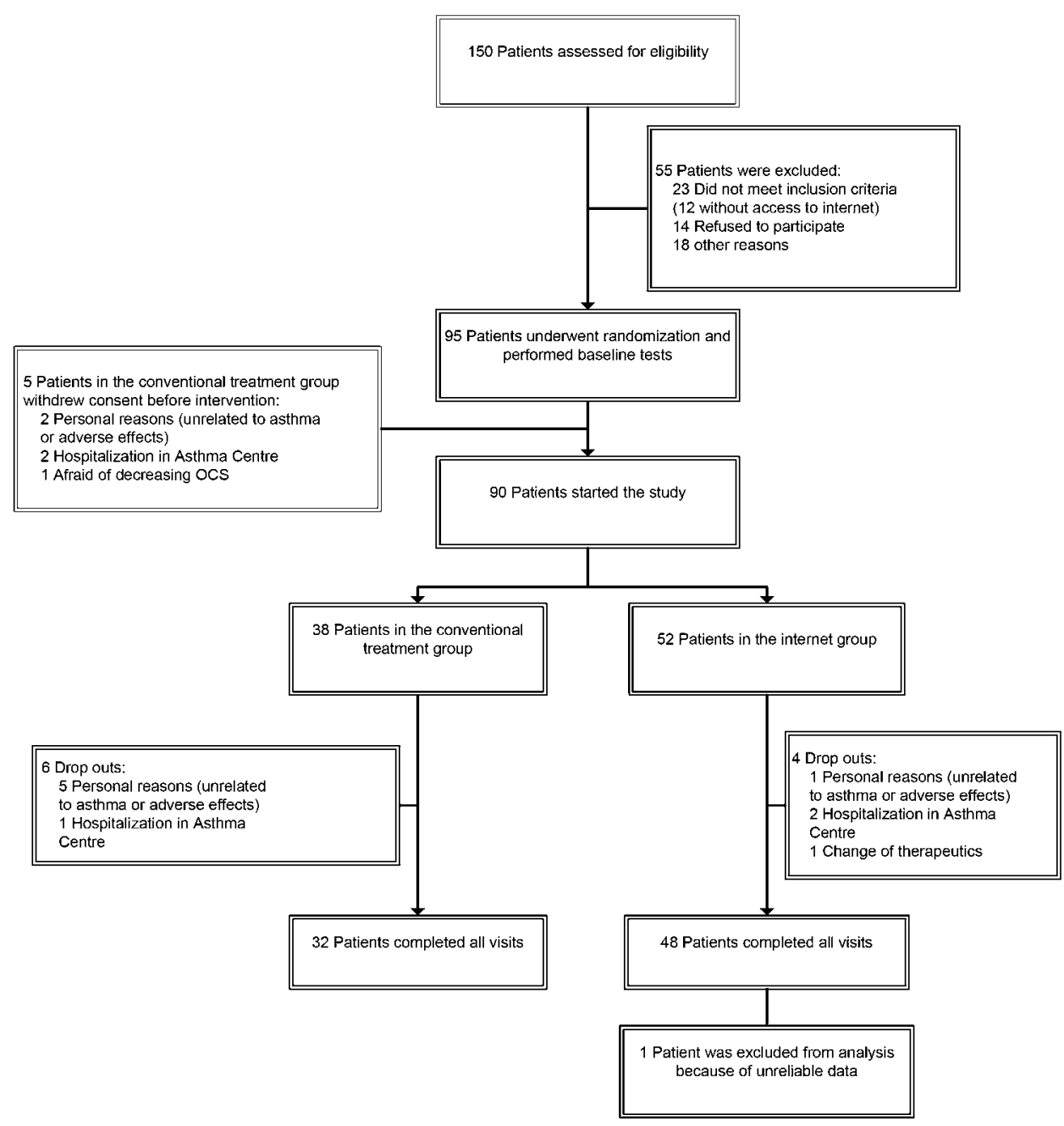


analysed with mixed effects regression models including time, treatment strategy and their interaction as covariates, and with random patient effects for the intercept and the regression weight of time on oral corticosteroid treatment. The effect of time was modelled with a linear model and the goodness of fit was checked by introducing higher order polynomial terms of time into the model. The fit of the covariance structure of the residuals was checked by extending the model with an autoregressive structure. Histograms of the residuals were further inspected for normality. The main trend in the average change with time of the average corticosteroid usage was summarised with the change rate estimated from the linear model.

The repeated measurements of the ACQ and AOLO were analysed in a similar fashion but the dependent variables were the change from baseline ACQ and AOLO, respectively. The effect of time on average change in ACQ and AQLO was modelled non-parametrically and summarised with the change from baseline ACO and AOLO averaged over all repeated measurements during follow-up.

\section{RESULTS}

Ninety-five patients were randomised from November 2007 to October 2008. Five patients in the conventional management group withdrew consent before the study had started and one patient was excluded from the study because of poor adherence to the trial protocol (figure 1). Eighty-nine patients were included in the intention-to-treat analysis (table 2); 51 and 38 patients were randomised to internet-based and conventional management, respectively. Randomisation was stratified without using allocation blocks, which explained the unequal number of patients in each study group.

The median dose of prednisone equivalent at study entry was 10 (25-75th percentile 5-15) $\mathrm{mg} /$ day in the internet group and 10 (5-15) $\mathrm{mg} /$ day in the conventional management group $(p=0.26)$. Other baseline characteristics of the study groups were equally similar (table 2).

\section{Sparing of oral corticosteroids}

The median cumulative sparing of prednisone equivalent in 6 months was 205 (25-75th percentile -221 to 777 ) $\mathrm{mg}$ in the internet group compared with $0(-497$ to 282$) \mathrm{mg}$ in the conventional management group $(p=0.02$, table 3$)$.

Mixed effects regression model analysis showed a total decrease in daily prednisone requirement from baseline of $-4.79 \mathrm{mg} /$ day (daily decrease of -0.019 (SE 0.0014) in the internet group compared with $+1.59 \mathrm{mg} /$ day (daily increase +0.001 (SE 0.0032)) in the conventional management group $(p<0.001$, figure 2$)$. Ten of 51 patients in the internet group and none of the patients in the conventional management group $(p=0.004)$ managed to taper their oral corticosteroid dose to $0 \mathrm{mg}$, with a mean (SD) duration of 79.7 (12.8) oral corticosteroid-free days over 6 months.

\section{ACO and AOLO}

Asthma control remained stable in both groups with a mean change in ACQ score of 0.26 (95\% CI 0.07 to 0.45$)$ and 0.12 (95\% $\mathrm{CI}-0.12$ to 0.36$)$ in the internet group and conventional management groups, respectively $(p=0.37)$.

Similarly, changes in asthma-related quality of life did not differ between the study groups (table 3 ) with mean changes in the AOLQ score of -0.03 (95\% CI -0.24 to 0.18$)$ and $0.14(95 \%$ $\mathrm{CI}-0.13$ to 0.41$)$ in the internet and conventional management groups, respectively $(p=0.30)$.

\section{Secondary and additional outcomes}

Changes in $\mathrm{FEV}_{1}$, number of asthma exacerbation, days of hospitalisation and patients' global satisfaction with the strategy were not different between the two groups (table 3 ).

The median (range) change in dose of ICS was 125 ( -250 to 250) $\mu \mathrm{g} /$ day in the conventional management group versus no change ( 0 to 250$) \mu \mathrm{g} /$ day in the internet strategy group $(\mathrm{p}<0.01)$.

\section{Monitoring adverse events}

Three patients had newly diagnosed severe adverse effects (diabetes in two patients and glaucoma in one patient).

\section{Internet algorithm}

Compliance with measuring $\mathrm{FEV}_{1}, \mathrm{FE}_{\mathrm{NO}}, \mathrm{ACQ}$ and entering the data into the website was very high $(88.8 \%$ in the conventional treatment group, $89.6 \%$ in the internet strategy group and $89.3 \%$ in the whole group).

The computer algorithm was overruled by the pulmonologist in 37 of 1023 decisions. The main reasons for these were to slow down the pace of steroid tapering $(65 \%)$, to treat an exacerbation $(9.7 \%)$ or to increase the oral corticosteroid dose based on clinical grounds (9\%). On eight occasions the patients themselves decided not to follow the computer advice for a variety of reasons.

$\mathrm{ACQ}$ and $\mathrm{FE}_{\mathrm{NO}}$ contributed to the decisions of the computer algorithm in 859 (84\%) and 164 (16\%) cases, respectively (table 4). There was no difference in total sparing dose of oral

Table 2 Baseline characteristics of subjects in the intention-to-treat population

\begin{tabular}{|c|c|c|}
\hline Patient characteristic & $\begin{array}{l}\text { Internet group } \\
(\mathrm{n}=51)\end{array}$ & $\begin{array}{l}\text { Conventional } \\
\text { management } \\
\text { group }(n=38)\end{array}$ \\
\hline Age (years) & $48.5( \pm 12.4)$ & $52.4( \pm 11.7)$ \\
\hline Male sex, $\mathrm{n}(\%$ total $\mathrm{n})$ & $23(45)$ & $18(47)$ \\
\hline Body mass index & $28.3( \pm 5.4)$ & $30( \pm 8.8)$ \\
\hline Atopy, $\mathrm{n}(\%$ total $\mathrm{n})$ & $23(45)$ & $19(50)$ \\
\hline Age of asthma onset (years) & $26(4-42)$ & $24.5(3-40)$ \\
\hline Duration of daily OCS use (months) & $36(12-132)$ & $46(12-120)$ \\
\hline Dose of prednisone (mg/day) & $10(5-15)$ & $10(5-15)$ \\
\hline Dose of ICS $(\mu \mathrm{g} / \mathrm{day})^{*}$ & $1250(750-1500)$ & $1000(750-1500)$ \\
\hline Never smokers, $\mathrm{n}(\%$ total $\mathrm{n})$ & $30(58.8)$ & $21(55.3)$ \\
\hline Pack-years (only ever smokers) & $3(3.1-9.7)$ & $5(3.6-12)$ \\
\hline \multicolumn{3}{|l|}{ Pre-bronchodilator $\mathrm{FEV}_{1} \dagger$} \\
\hline Litres & $2.52( \pm 1.02)$ & $2.40( \pm 1.42)$ \\
\hline$\%$ Predicted & $76.3( \pm 24.7)$ & $71.3( \pm 21)$ \\
\hline Change in $\mathrm{FEV}_{1}$ after $\beta_{2}(\%) \dagger$ & $7.2(1.3-13.5)$ & $8.5(3.1-18)$ \\
\hline \multicolumn{3}{|l|}{ Pre-bronchodilator $\mathrm{FVC} \dagger$} \\
\hline Litres & $3.24( \pm 1.5)$ & $3.58( \pm 0.9)$ \\
\hline$\%$ Predicted & $113( \pm 11.1)$ & $94( \pm 15.5)$ \\
\hline $\mathrm{FEV}_{1} / \mathrm{FVC}$ ratio & $0.63( \pm 0.18)$ & $0.69( \pm 0.49)$ \\
\hline Exhaled nitric oxide $(\mathrm{ppb}) \dagger$ & $38(18-81)$ & $34(13-75)$ \\
\hline Juniper ACQ scoreł & $2.2( \pm 1.11)$ & $2.5( \pm 0.95)$ \\
\hline Juniper AOLO score§ & $5.0( \pm 1.06)$ & $4.6( \pm 1.18)$ \\
\hline
\end{tabular}

Data are presented as median (25-75th percentile) or mean \pm SD unlessotherwise stated Atopy is defined as at least one positive radioallergosorbent test for common aeroallergens. All $p$ values are $>0.05$

*The doses of all ICS were converted to the equivalent dose of fluticasone. $+\mathrm{FEV}_{1}, \mathrm{FVC}$ and exhaled nitric oxide measured at study baseline visit.

$\ddagger$ The Juniper Asthma Control Questionnaire score ranges from 0 to 7 , with higher scores indicating worse control.

$\S$ The Juniper Quality of Life Questionnaire score ranges from 1 to 7 , with higher scores indicating better quality of life.

ACO, Asthma Control Questionnaire; AOLO, Asthma Quality of Life Questionnaire; FEV forced expiratory volume in $1 \mathrm{~s}$; FVC, forced vital capacity; ICS, inhaled corticosteroids OCS, oral corticosteroids; ppb, parts per billion. 
Table 3 Primary and secondary outcomes according to treatment group

\begin{tabular}{|c|c|c|c|c|}
\hline Variable & $\begin{array}{l}\text { Internet group } \\
(\mathrm{n}=51)\end{array}$ & $\begin{array}{l}\text { Conventional management } \\
\text { group }(n=38)\end{array}$ & $\begin{array}{l}\text { Absolute difference* } \\
\text { (95\% CI) }\end{array}$ & p Value \\
\hline Sparing of prednisone in 6 months $(\mathrm{mg})$ (median, $25-75$ th percentile) $\dagger$ & $205(-221$ to 777$)$ & $0(-497.5$ to 282$)$ & 205 (45 to 365$)$ & 0.02 \\
\hline Mean (SE) ACQ change from baseline $\neq \S$ & $0.26(0.09)$ & $0.12(0.12)$ & $0.14(-0.14$ to 0.42$)$ & 0.37 \\
\hline Slope $\mathrm{FEV}_{1}(1) \ddagger$ & -0.0009 & -0.0007 & $0.0002(-0.0012$ to 0.0018$)$ & 0.73 \\
\hline Exacerbations per patient (median, $25-75$ th percentile) & $1(0$ to 1$)$ & $1(0$ to 1$)$ & 0 & 0.78 \\
\hline Exacerbations per year (median, 25-75th percentile) ${ }^{* *}$ & $1.68(0$ to 3.9$)$ & $1.82(0$ to 2.5$)$ & -0.14 & 0.95 \\
\hline Mean (SE) global satisfaction scale $\neq \ddagger$ & $5.58(0.2)$ & $6.08(0.18)$ & $0.5(-0.07$ to 1.06$)$ & 0.09 \\
\hline
\end{tabular}

*Absolute difference is the difference in medians or means between the groups.

†Sparing of prednisone is the difference between the expected cumulative dose (daily dose at study entry multiplied by the number of days in the study) and the actual cumulative dose. For the calculation of the actual cumulative dose we used the dose registered daily on the website by each patient.

$\ddagger$ Values are model estimates of mixed effects regression models.

$\S$ The Juniper Asthma Control Questionnaire (ACQ) score ranges from 0 to 7, with higher scores indicating worse control.

TThe Juniper Quality of Life Questionnaire (AOLO) score ranges from 1 to 7 , with higher scores indicating better quality of life.

**Incidence of exacerbations/year (number of exacerbations per patient divided by the number of days in the study and multiplied by 365 ).

† Incidence of days of hospitalisations/patient/year (number of days of hospitalisation per patient divided by the number of days in the study multiplied by 365 )

$\ddagger \ddagger$ Patients' rate for their satisfaction with the tapering strategy from 1 (absolutely not satisfied) to 7 (really satisfied).

corticosteroids between patients who had or had not $\mathrm{FE}_{\mathrm{NO}}$ related decisions by the algorithm $(482.7 \pm 1223 \mathrm{mg}$ vs 462.12 $\pm 455 \mathrm{mg}, \mathrm{p}=0.83$ ).

\section{DISCUSSION}

This study shows that an internet-based management tool has the potential to decrease total corticosteroid consumption in patients with steroid-dependent asthma compared with conventional treatment over a period of 6 months without compromising asthma control or asthma-related quality of life. These results suggest that a strategy based on intensive internet monitoring of objective measures of asthma control should be considered as a safe and feasible way to adjust the dose of oral corticosteroids in patients with severe asthma.

There is very little information available in the literature on how to taper oral corticosteroids safely in asthma after prolonged use. The adjustment of ICS guided by objective parameters of airway disease has been addressed in several other studies. The use of airway responsiveness, ${ }^{26}$ eosinophils in

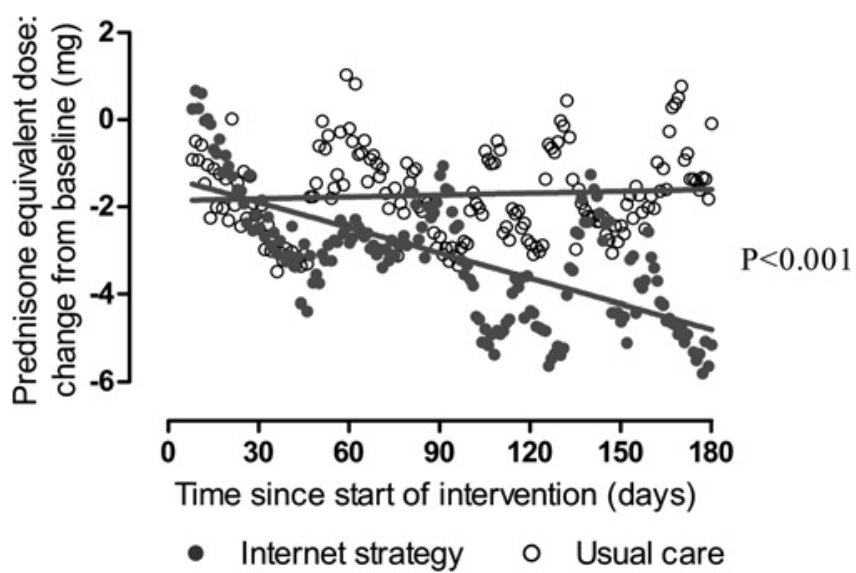

Figure 2 Changes in maintenance dose of corticosteroids over 6 months. The figure shows the change in maintenance dose of prednisone from baseline in each study group over the course of 180 days. Closed and open circles represent the mean daily changes in prednisone equivalent in the internet group and conventional management group, respectively; lines represent the slope from the mixed effects regression model $(p<0.001$ for comparison between the two groups). induced sputum ${ }^{27}$ and $\mathrm{FE}_{\mathrm{NO}}{ }^{28} 29$ appear to be superior over usual care in most studies, although for $\mathrm{FE}_{\mathrm{NO}}$ there has been some controversy. ${ }^{30-32}$ In contrast to these previous studies, the aim of our study was not to evaluate the use of $\mathrm{ACQ}$ or $\mathrm{FE}_{\mathrm{NO}}$ in adjusting the corticosteroid dose but to use these measures as part of an integrated multifaceted approach including internet-supported monitoring and continuous supervision by a specialised asthma nurse.

We compared the effectiveness of two clinical strategies using a pragmatic approach ${ }^{19}$ according to CONSORT guidelines. ${ }^{22}$ In this approach the use of placebo or sham is not recommended to assess the relative benefits versus harms of different treatment strategies in order to make it more representative of actual practice. ${ }^{19}$ Patients in our study were aware of their randomisation group and knew that they would receive tapering instructions either on a weekly basis from the computer or by the treating physician on a monthly basis. Blinding the patients would therefore not only be futile but also diverge from the pragmatic concept.

One could argue that belief in the novel internet approach, extra effort and optimism might have positively influenced the effectiveness of the internet-based management tool. However, given the fact that the patients' global satisfaction with both tapering strategies was similar and even tended to be in favour of conventional asthma treatment, this seems highly unlikely. The

Table 4 Contribution of fraction of exhaled nitric oxide $\left(\mathrm{FE}_{\mathrm{NO}}\right)$ and Asthma Control Questionnaire (ACQ) to algorithm decisions

\begin{tabular}{lll}
\hline & $\Delta$ ACQ $\geq+\mathbf{0 . 5}$ & $\Delta$ ACO $<+0.5$ \\
\hline$\Delta \mathrm{FE}_{\mathrm{NO}}>+10 \mathrm{ppb}$ and $>10 \%$ & OCS $\uparrow$ & OCS $\downarrow$ \\
$\Delta \mathrm{FE}_{\mathrm{NO}}>+10 \mathrm{ppb}$ and $\leq 10 \%$ & $36(3.5 \%)^{*}$ & $128(12.5 \%)^{*}$ \\
& No change in OCS & OCS $\downarrow$ \\
$-10 \leq \Delta \mathrm{FE}_{\mathrm{NO}} \leq+10 \mathrm{ppb}$ & $1(0.1 \%)^{*}$ & $3(0.3 \%)^{*}$ \\
& No change in OCS & OCS $\downarrow$ \\
$\Delta \mathrm{FE}_{\mathrm{NO}}<-10 \mathrm{ppb}$ & $105(10.3 \%)^{*}$ & $621(60.7 \%)^{*}$ \\
& OCS $\downarrow$ & OCS $\downarrow$ \\
& $22(2.2 \%)^{*}$ & $107(10.5 \%)^{*}$ \\
\hline
\end{tabular}

*Number of observed decisions (and their relative percentage to the total number of interventions) corresponding to the different algorithm possibilities in the internet management group over a 6-month period.

$\triangle \mathrm{ACO}$, difference in Asthma Control Questionnaire scores between 2 weeks; $\Delta \mathrm{FE}_{\mathrm{NO}}$, difference in mean fraction of exhaled nitric oxide (in parts per billion) between 2 weeks; $\uparrow \mathrm{OCS}$, increase in prednisone dose by one step; $\downarrow$ OCS, decrease in prednisone dose by one dose step. 
success of the internet-based strategy therefore does not seem to be biased by enthusiasm for the new intervention.

The design of the tapering algorithm was such that stable symptoms (increase in ACQ <0.5) would always lead to a reduction in corticosteroid dose and increased symptoms (increase in $A C Q \geq 0.5$ ) only to a step-up in dose if there was a concomitant increase in $\mathrm{FE}_{\mathrm{NO}}$. This was to avoid overtreatment in patients with corticosteroid withdrawal symptoms or discordance between symptom expression and inflammation. ${ }^{33}$ Post hoc analysis showed that weekly ACQ (with FEV 1 included) was the major driver of the algorithm decision, suggesting that corticosteroid sparing could have occurred without daily measures of $\mathrm{FE}_{\mathrm{NO}}$. Whether daily $\mathrm{FE}_{\mathrm{NO}}$ measurements have additional value in predicting exacerbations in these patients is as yet unknown.

The major advantage of the internet-based management tool in the present study is twofold: (1) it uses frequent objective measures of asthma control and (2) it provides the possibility of daily communication and feedback with an asthma nurse. Together, this allows rapid and safe adjustment of the corticosteroid dose under continuous supervision which is not practicable in a conventional treatment setting. A sparing of $205 \mathrm{mg}$ prednisone in 6 months is a significant clinical benefit given that a difference of $55 \mathrm{mg}$ in 6 months is associated with adjusted ORs of 9.2 for vertebral fracture, 3.1 for cataracts and 3.3 for muscle weakness. ${ }^{3}$

The use of internet-based therapies combined with novel technologies to assess disease severity will become more common in future healthcare. ${ }^{13-17}$ Such technologies may allow centralised continuous long distance support of patients, improve the quality of care and reduce the time and efforts required for intensive monitoring processes such as tapering of oral corticosteroids. The implementation of internet-based management tools in real life would therefore increase patient safety and improve the communication between patients and caregivers.

In conclusion, we have shown that, in patients with severe prednisone-dependent asthma, oral corticosteroids can be successfully titrated by the use of an internet-based management tool. The internet-based strategy is feasible for almost all patients, and is ideal for use in clinical practice and is also a suitable tool for assessing outcome in clinical trials of novel antiinflammatory steroid-sparing drugs. ${ }^{34} 35$ In fact, this personalised medicine approach might be one of the first examples of how patients with severe respiratory chronic diseases might benefit from interactive internet-based treatment strategies.

Acknowledgements The authors thank Petra Hirmann, MarijkeAmelink, Paul van Spiegel, Christian Melissant, Lous Rijssenbeek, Renske van der Meer, Bita Hajian, Michael van Hengstum, the lung function departments of the Academic Medical Centre Amsterdam, Medical Center Leeuwarden, HagaZiekenhuis, Medisch Spectrum Twente, Leiden University Medical Center, St Franciscus Gasthuis and all participating patients.

Funding This study was funded by The Netherlands Organization for Health Research and Development (ZonMw). Equipment for the analysis of nitric oxide was provided by Aerocrine-AB in April 2007. The funding sources had no role in the study design, data collection, analysis or interpretation, or in the decision to submit this article for publication.

\section{Competing interests None.}

Patient consent All patients provided written informed consent.

Ethics approval The study was approved by the ethics committee of all participating institutions (Academic Medical Centre, University of Amsterdam, Amsterdam; Medical Center Leeuwarden, Leeuwarden; HagaZiekenhuis, Den Haag; Medisch Spectrum Twente, Enschede; Leiden University Medical Center, Leiden; St Franciscus Gasthuis, Rotterdam, The Netherlands).
Contributors The authors were solely responsible for the study design, data analysis and interpretation and for the writing of the manuscript. All authors had equal participation.

Provenance and peer review Not commissioned; externally peer reviewed.

\section{REFERENCES}

1. American Thoracic Society. Proceedings of the ATS workshop on refractory asthma: current understanding, recommendations, and unanswered questions. Am J Respir Crit Care Med 2000;162:2341-51.

2. Chung KF, Godard P, Adelroth E, et al. Difficult/therapy-resistant asthma: the needfor an integrated approach to define clinical phenotypes, evaluate risk factors, understand pathophysiology and find novel therapies. ERS Task Force on Difficult/ Therapy-Resistant Asthma. European Respiratory Society. Eur Respir J 1999;13:1198-208

3. Walsh LJ, Wong CA, Oborne J, et al. Adverse effects of oral corticosteroids in relation to dose in patients with lung disease. Thorax 2001;56:279-84.

4. Huscher D, Thiele K, Gromnica-Ihle E, et al. Dose-related patterns of glucocorticoidinduced side effects. Ann Rheum Dis 2009:68:1119-24.

5. Moore WC, Bleecker ER, Curran-Everett D, et al. Characterization of the severe asthma phenotype by the National Heart, Lung, and Blood Institute's Severe Asthma Research Program. J Allergy Clin Immunol 2007;119:405-13.

6. National Institutes of Health. National Heart, Lung, and Blood Institute. Globallnitiative for Asthma. Global strategy for asthma management and prevention. NHLBI/WHO Workshop Report 2008. http://www.ginasthma.org/ laccessed Oct 2010).

7. McGeehan M, Busse WW. Refractory asthma. Med Clin North Am 2002;86:1073-90.

8. Heaney LG, Conway E, Kelly C, et al. Predictors of therapy resistant asthma: outcome of a systematic evaluation protocol. Thorax 2003;58:561-6.

9. Ito $\mathbf{K}$, Chung KF, Adcock IM. Update on glucocorticoid action and resistance. J Allergy Clin Immunol 2006;117:522-43.

10. Reed CE. The natural history of asthma in adults: the problem of irreversibility. J Allergy Clin Immunol 1999;103:539-47.

11. Dixon RB, Christy NP. On the various forms of corticosteroid withdrawal syndrome. Am J Med 1980;68:224-30.

12. Lester RT, Ritvo P, Mills EJ, et al. Effects of a mobile phone short message service on antiretroviral treatment adherence in Kenya (WelTel Kenya1): a randomised trial. Lancet 2010;376:1838-45.

13. Holbrook A, Thabane L, Keshavjee K, et al. Individualized electronic decision support and reminders to improve diabetes care in the community: COMPETE II randomized trial. CMAJ 2009:181:37-44.

14. McManus RJ, Mant J, Bray EP, et al. Telemonitoring and self-management in the control of hypertension (TASMINH2): a randomised controlled trial. Lancet 2010;376:163-72.

15. Rasmussen LM, Phanareth $\mathrm{K}$, Nolte $\mathrm{H}$, et al. Internet-based monitoring of asthma: a long-term, randomized clinical study of 300 asthmatic subjects. J Allergy Clin Immunol 2005:115:1137-42.

16. van der Meer V, Bakker MJ, van den Hout WB, et al. Internet-based selfmanagement plus education compared with usual care in asthma: a randomized trial. Ann Intern Med 2009;151:110-20.

17. Morlion B, Knoop C, Paiva M, et al. Internet-based home monitoring of pulmonary function after lung transplantation. Am J Respir Crit Care Med 2002;165:694-7

18. Silkoff PE, Carlson M, Bourke T, et al. The Aerocrine exhaled nitric oxide monitoring system NIOX is cleared by the US Food and Drug Administration for monitoring therapy in asthma. J Allergy Clin Immunol 2004;114:1241-56.

19. Krishnan JA, Schatz M, Apter AJ. A call for action: comparative effectiveness research in asthma. J Allergy Clin Immunol 2010;127:123-7.

20. Smith JR, Mildenhall S, Noble MJ, et al. The Coping with Asthma Study: a randomised controlled trial of a home based, nurse led psycho educational intervention for adults at risk of adverse asthma outcomes. Thorax 2005;60:1003-11.

21. Relton C, Torgerson D, O'Cathain A, et al. Rethinking pragmatic randomised controlled trials: introducing the "cohort multiple randomised controlled trial" design. BMJ 2010;340:c1066.

22. Zwarenstein $\mathbf{M}$, Treweek $\mathrm{S}$, Gagnier JJ, et al. Improving the reporting of pragmatic trials: an extension of the CONSORT statement. BMJ 2008;337:a2390.

23. American Thoracic Society. ATS/ERS recommendations for standardized procedures for the online and offline measurement of exhaled lower respiratory nitric oxide and nasal nitric oxide. Am J Respir Crit Care Med 2005;171:912-30.

24. Juniper EF, Svensson K, Mork AC, et al. Measurement properties and interpretation of three shortened versions of the asthma control questionnaire. Respir Med 2005;99:553-8.

25. Juniper EF, Guyatt GH, Willan A, et al. Determining a minimal important change in a disease-specific Quality of Life Questionnaire. J Clin Epidemiol 1994;47:81-7.

26. Sont JK, Willems LN, Bel EH, et al; The AMPUL Study Group. Clinical control and histopathologic outcome of asthma when using airway hyperresponsiveness as an additional guide to long-term treatment. Am J Respir Crit Care Med 1999;159:1043-51.

27. Green RH, Brightling CE, McKenna S, et al. Asthma exacerbations and sputum eosinophil counts: a randomized controlled trial. Lancet 2002;360:1715-21. 
28. Pijnenburg MW, Bakker EM, Hop WC, et al. Titrating steroids on exhaled nitric oxide in children with asthma: a randomized controlled trial. Am J Respir Crit Care Med 2005;172:831-6.

29. Smith AD, Cowan J0, Brassett KP, et al. Use of exhaled nitric oxide measurements to guide treatment in chronic asthma. N Engl J Med 2005;352:2163-73.

30. Barnes PJ, Dweik RA, Gelb AF, et al. Exhaled nitric oxide in pulmonary diseases: a comprehensive review. Chest 2010;138:682-92.

31. Petsky HL, Cates CJ, Lasserson TJ, et al. A systematic review and meta-analysis: tailoring asthma treatment on eosinophilic markers (exhaled nitric oxide or sputum eosinophils). Thorax Published Online First: 11 October 2010. doi:10.1136/ thx.2010.135574
32. Szefler SJ, Mitchell H, Sorkness CA, et al. Management of asthma based on exhaled nitric oxide in addition to guideline-based treatment for inner-city adolescents and young adults: a randomized controlled trial. Lancet 2008:372:1065-72.

33. Haldar P, Pavord ID, Shaw DE, et al. Cluster analysis and clinical asthma phenotypes. Am J Respir Crit Care Med 2008:178:218-24.

34. Haldar P, Brightling CE, Hargadon B, et al. Mepolizumab and exacerbations of refractory eosinophilic asthma. N Engl J Med 2009;360:973-84.

35. Nair P, Pizzichini MM, Kjarsgaard $M$, et al. Mepolizumab for prednisonedependent asthma with sputum eosinophilia. N Engl J Med 2009;360:985-93

\section{Journal club}

\section{Inhaled nitric oxide does not prevent bronchopulmonary dysplasia}

The use of nitric oxide in premature infants at risk of developing bronchopulmonary dysplasia is controversial, although it improves gas exchange in animal models. This study tested the hypothesis that inhaled low concentration nitric oxide started early in babies with mild respiratory failure reduces the incidence of bronchopulmonary dysplasia.

Eight hundred preterm infants with a gestational age at birth between 24 and 29 weeks, weighing at least $500 \mathrm{~g}$, requiring surfactant or continuous positive airway pressure for respiratory distress within $24 \mathrm{~h}$ of birth were included in this double-blind, multicentre randomised controlled trial. Three hundred and ninety-nine infants were randomly assigned to low-dose inhaled nitric oxide and 401 to placebo gas for a minimum of seven and a maximum of 21 days.

Treatment with inhaled nitric oxide and placebo did not result in significant differences in survival of infants without the development of bronchopulmonary dysplasia or in the development of bronchopulmonary dysplasia.

This study showed no benefit with low-dose inhaled nitric oxide as a preventive treatment strategy in premature babies at risk of developing bronchopulmonary dysplasia.

- Mercier JC, Hummler H, Durrmeyer X, et al; for the EUNO Study Group. Inhaled nitric oxide for prevention of bronchopulmonary dysplasia in premature babies (EUNO): a randomised controlled trial. Lancet 2010;376:346-54.

\section{A Bhatta}

Correspondence to A Bhatta, ST3 Respiratory Medicine, Royal Albert Edward Infirmary, Wigan, Wing12, Block 1, Leigh Infirmary, The Avenue, Leigh WN71HS, UK; amrith.bhatta@doctors.org.uk

Published Online First 27 September 2010

Thorax 2011;66:520. doi:10.1136/thx.2010.149922 